\title{
Craniofacial injuries in professional cricket: no more a red herring
}

\author{
Manjul Tripathi, MCh, Dhaval P. Shukla, MCh, Dhananjaya Ishwar Bhat, MCh, \\ Indira Devi Bhagavatula, MCh, and Tejesh Mishra, MBBS
}

Department of Neurosurgery, National Institute of Mental Health and Neuro Sciences, Bangalore, India

\begin{abstract}
The issue of head injury in a noncontact sport like cricket is a matter of great debate and it carries more questions than answers. Recent incidents of fatal head injuries in individuals wearing a helmet have caused some to question the protective value of the helmet. The authors discuss the pattern, type of injury, incidents, and location of cranio-facio-ocular injuries in professional cricket to date. They evaluate the history of usage of the helmet in cricket, changes in design, and the protective value, and they compare the efficacy of various sports' helmets with injury profiles similar to those in cricket. The drop test and air cannon test are compared for impact energy attenuation performance of cricket helmets. A total of 36 cases of head injuries were identified, of which $5(14 \%)$ were fatal and $9(22 \%)$ were career-terminating events. Batsmen are the most vulnerable to injury, bearing $86 \%$ of the burden, followed by wicketkeepers ( $8 \%$ ) and fielders (5.5\%). In $53 \%$ of cases, the ball directly hit the head, while in $19.5 \%$ of cases the ball entered the gap between the peak and the faceguard. Ocular injuries to 3 wicketkeepers proved to be career-terminating injuries. The air cannon test is a better test for evaluating cricket helmets than the drop test. Craniofacial injuries are more common than popularly believed. There is an urgent need to improve the efficacy and compliance of protective restraints in cricket. A strict injury surveillance system with universal acceptance is needed to identify the burden of injuries and modes for their prevention. http://thejns.org/doi/abs/10.3171/2016.2.FOCUS15341
\end{abstract}

KEY WORDS cricket; helmet; protective gears; ball; batsman; head injury; concussion

$\mathrm{S}$ INCE the introduction of cricket, it has been proudly called a "gentleman's game." In recent years, player safety has come up as an important concern. With increased awareness for concussion, there has been a noticeable increase in athletes wearing helmets and other safety restraints. Skiing, snowboarding, and cycling have all witnessed increased awareness for helmet usage, even outside of competition. ${ }^{2,4-6}$ In the last 4 decades, the helmet has been used more often; still, it is not a compulsory part of a batsman's kit. The increase in number of tournaments, newer formats of the game, and better modalities for identification of injuries have highlighted the importance of safety parameters and restraints to prevent such injuries. Being a noncontact sport, cricket is considered to carry minimal risk compared with sports such as ice hockey and American football. However, recent incidents of head injuries refute this notion and demand research for better design and strict use of safety restraints. . $5,16,26,27-30,32^{2}$

\section{Methods}

The literature and Internet were searched with cricket, helmet, concussion, headgear, skull, head, and eye injury as keywords. An intense search was performed for incidents of craniofacial injury in the history of professional, county, and first-class cricket played throughout the world. Various injury surveillance reports published by international and national cricket councils were also searched. ${ }^{15-18,20-22,27,29,31}$ We have reviewed the pattern of head injury and different evaluation parameters for helmet safety in other contemporary sports and helmet designs. ${ }^{10,15-18,34,35}$ Spine trauma and other polytrauma are not included in this analysis.

\section{Results}

During 1870-2015, a total of 36 events of craniofacial injuries were identified, of which $5(14 \%)$ were fatal and 9 $(22 \%)$ were career-terminating events (Table 1). Six inju-

ABBREVIATIONS ICC = International Cricket Council. 
ries (16.5\%) involved a major injury to the eye and required surgical intervention. In 3 cases $(8 \%)$, ocular injury proved to be the cause of premature retirement from the sport. In 19 cases (53\%), a direct hit by a speeding ball caused injury, and in 7 cases (19.5\%) the ball entered through the grill in between the peak and faceguard.

Batsmen were the most vulnerable, with $31(86 \%)$ bearing the injury burden, followed by wicketkeepers $(3 ; 8 \%)$ and fielders $(2 ; 5.5 \%)$. The most common pattern of injury to wicketkeepers was injury to the eye by the bail, especially while fielding for a spin bowler. Injury while fielding at ground is a relatively rare event, accounting for only 2 injuries (5.5\%). However, it also includes fatal injuries to the Indian players Raman Lamba and Ankit Keshari. ${ }^{15-18}$

\section{Review of the Literature}

At present, cricket is a very popular sport, played in more than 105 countries throughout the world. ${ }^{9}$ The International Cricket Council (ICC) is the governing body of cricket, with 10 full member, 38 associate member, and 57 affiliate member countries. The ICC organizes a Cricket World Cup tournament every 4th year. This tournament is the world's third largest sporting event, with only the Fédération Internationale de Football Association (FIFA) World Cup and the Summer Olympics exceeding it. ${ }^{22}$ Both male and female teams play cricket in different formats, such as One Day International, Test match, and Twenty20. Various national and international governing bodies also organize under 12-year, under 16-year, and regular cricket matches at regional, national, and international levels independently. In countries like India, children from various socioeconomic strata play leisure cricket not only in the fields and parks but also in crowded areas such as roads and streets, adding propensity for increased number of injuries caused by cricket and road traffic accidents.

Professional cricket is a noncontact sport in which a bowler delivers a hard ball toward a batsman at a speed of $80-160 \mathrm{~km} / \mathrm{h}(50-100 \mathrm{mph})$ from a distance of $20 \mathrm{~m}$ (22 yds). Most of the time, the injuries are unintentional, but infrequently balls are thrown targeting the bodyline out of anger, frustration, or in the heat of sledging. ${ }^{14-18,21,22}$ The impact may be minor to severe, but an ideal helmet should provide full protection to the head from every possible injury. A batsman can only play his/her natural game if the fierce pace does not intimidate him/her, and wearing a helmet provides this assurance.

\section{Injury Surveillance in Professional Cricket}

The aim of this study was to analyze the spectrum of possible injuries to the head and face in professional cricket. An isolated news report of head injury during cricket matches creates a misconception that injuries in cricket are rare events. However, it is not really a red herring. Injury surveillance by the England and Wales Cricket Board and ICC has documented nearly 50 cases of injuries to batsman..$^{26,27,35}$ In 2005, cricket narrowly preceded football and rugby union to the publication of the sport's first consensus statement of injury definition..$^{21,22,27}$ A few injury surveillance reports are available in cricket, dating back to World Cup tournaments of 2003 and 2011. These reports detail the overall injury prevalence rather than concentrate on craniofacial injuries. The injury prevalence rate in the injury surveillance report by the ICC has been reported to range from $10 \%$ to $15 \%$, classifying cricket as a game associated with a moderate injury risk in comparison with football and rugby. $8,21,22,27,33$

The reports were criticized as they covered only one format of cricket, i.e., One Day International. There was no formal analysis available for Twenty 20 and Test cricket-related injuries, as prolonged play, a tired player, and different degrees of pressure to perform change the vulnerability and spectrum of injuries. ${ }^{21,22,27}$ Another important shortcoming is the data collection from players of 5 of 14 countries only (Zimbabwe, Sri Lanka, South Africa, Bangladesh, and Pakistan). In the remaining 9 countries, the national cricket councils were independently collecting the data, which was not shared with the ICC. However, an initiative by the ICC to identify the current burden of injury, especially head injury in professional cricket, should be welcomed..$^{21,22,27}$ Injury surveillance in cricket has so far concentrated on injuries resulting in match time loss only, in comparison with football and rugby, where all injuries are reported. With the different formats of cricket being played year round, injury surveillance has become a rather difficult task because of independent clubs and ownerships failing to share data. In addition, player consent is still a major issue in reporting injuries to international agencies.

\section{Severity of Head Injury}

The spectrum of head injury in cricket ranges from trivial skull fractures to fatal accidents. The history of head injury in cricket parallels the history of cricket itself (Table 1). The first fatal injury dates back to 1870 , when a bouncer by John Platts hit George Summers on head. Summers was not wearing a helmet, and he died the next day. The next player, Richard Daft walked out with his head wrapped in a towel. ${ }^{15-18}$ Although head injuries kept happening in cricket, only isolated independent events were reported without any proper record. The risk and its severity were only gradually realized, and helmets became an essential safety kit of a batsman.

In previous nationwide surveys, Stretch and Raffan found that head and face injuries account for $9 \%-25 \%$ of injuries to batsmen..$^{33}$ Emergency data collection in Australia from 1989 to 1993 mentioned that $44.4 \%$ of all cricketrelated presentations in children and $16.6 \%$ in adults were for head injury. ${ }^{21}$ As in other sports, there may be underreporting of head injuries (mostly concussions). This may be because of the athlete minimizing the event to continue playing or it may not be perceived serious enough to be reported. ${ }^{1,4,5,8,29}$ Many players tend to underreport such an event and try to reenter the contest, denying any residual effect. In a minor head injury, the decision to continue to play or not is the decision of the player, and the opinion of a medical professional appears to be secondary. A professional player is obligated to play well and maintain onground appearance and charisma of not being soft on the targets. Since "walk and talk" injuries may predispose to second impact syndromes leading to catastrophic damage, caution should be exercised before allowing the player to return to the game or even net practice. 


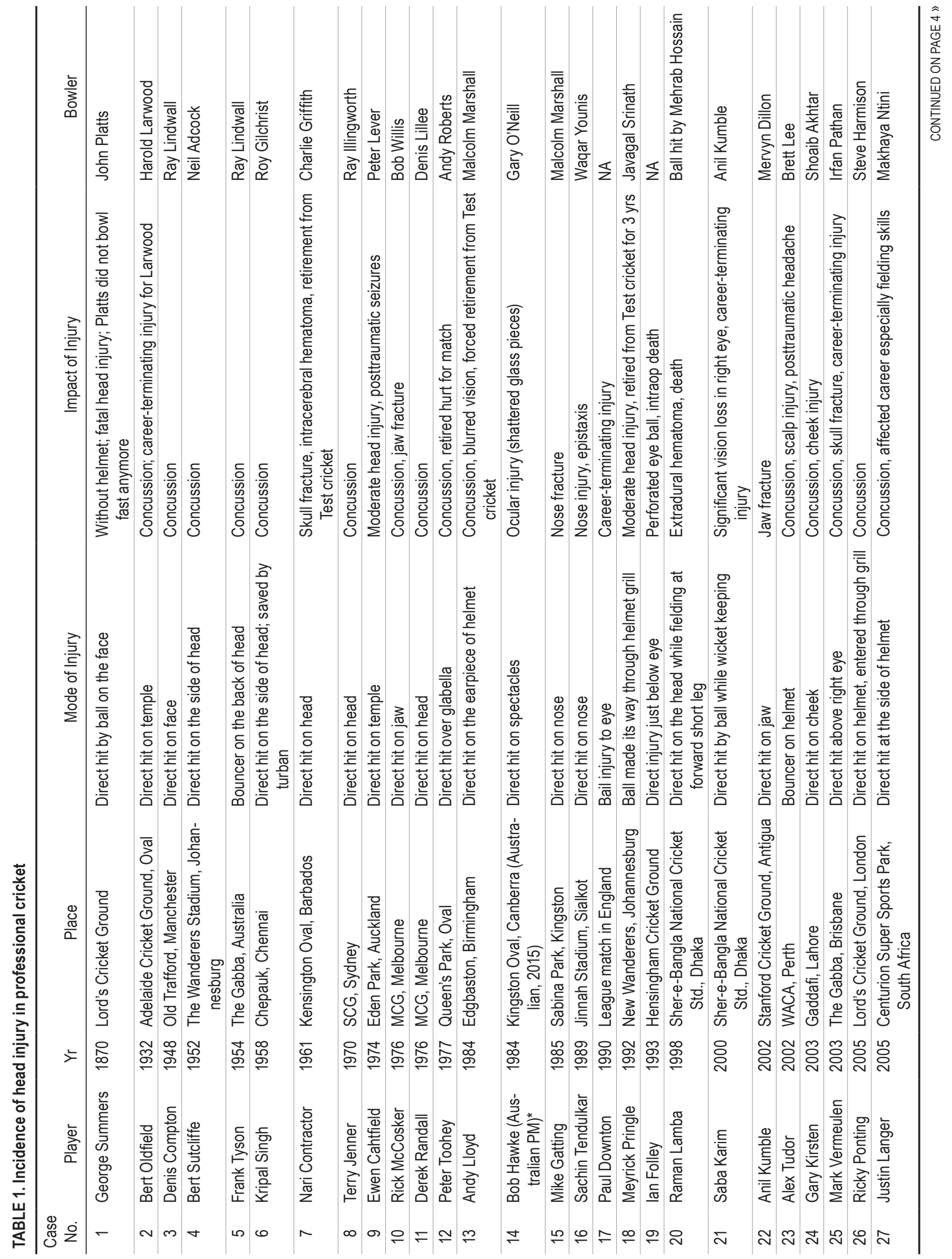


History of the Helmet in Cricket

In the early years, a helmet was not a part of a batsman's gear. However in 1860, the bowling pattern changed from underarm to overarm action and led to introduction of a new breed of bowlers called "pacers." In 1932-1933, the English cricket team adopted the infamous bodyline tactic to tame "run machine" Sir Don Bradman. It led to diplomatic debate and finally changed the laws of cricket. ${ }^{25}$ Since then, bouncers and beamers are striking the batsman's head at regular intervals. A bouncer (or bumper) is a type of fast delivery, pitched short on the pitch, so that it bounces well short of the batsman and rears up to chest or head height (or even higher). A beamer is an illegal delivery aiming at the batsman's head without bouncing on the pitch. Fierce pacers such as Malcolm Marshall, Andy Roberts, Joel Garner, Denise Lillee, and Jeff Thompson changed the face of the game in the 1970s and prompted the introduction of the helmet. In front of an express bowler delivering at a speed of 83-100 mph, a batsman has just $0.45-0.6$ seconds to analyze and hit the ball. With this, the helmet became popular and batsmen around the world are now using it as a protective gear.

\section{Helmet Designs}

Earlier batsmen used scarves, towels, and padded caps to protect themselves from the lethal impact. Patsy Hendren, an English cricketer was the first to use a specially designed protective cap in the 1930s. The first recorded use of a cricket helmet dates back to March 17, 1978, by Graham Neil Yallop, an Australian cricketer against the West Indies. The earlier helmets resembled full-faced motorcycle helmets in their design. They were heavy, hot, uncomfortable, and hampered the batsman's vision during long innings. At present, a cricket helmet has 2 primary components: a helmet shell and detachable faceguard usually in the form of a metal grill (Fig. 1A and B). In recent designs, plastic or carbon fiber shells with titanium grills have replaced the earlier heavy metallic material, making it lighter, but the design has remained nearly the same. The performance of any helmet is dependent on the liner foam (its thickness and density) and the shell stiffness. Normally, helmets have a size range of $54-58 \mathrm{~cm}$ with shell thickness of 3-4 $\mathrm{mm}$ and liner thickness of $8-10$ $\mathrm{mm} .{ }^{26,28}$

\section{Head Injuries With the Helmet in Place}

Soccer and ice hockey have been identified as the most dangerous sports as far as head injury is concerned. These are the games with the maximum chances of head-on collision leading to concussion injuries. Recent fatal accidents in professional cricket have highlighted the deficiencies in the existing helmet designs. ${ }^{2,6-8,16}$

Most midface injuries or nasal fractures have happened when a player was wearing a helmet. The ball rams into the face between the peak-faceguard gap, even if the gap was considerably smaller than the width of the ball. In the guidelines laid by British Standards (BS7928), the peakfaceguard gap should be $55 \mathrm{~mm}$ or smaller. The standard diameter of a cricket ball is $73 \mathrm{~mm}$. Even with a difference of $18 \mathrm{~mm}$, there have been incidents of the ball entering 
through this gap, leading to severe cranio-facio-maxillary injuries..$^{20,28}$ Tampering with the grill by the batsman predisposes the batsman to the injury. The grill has often been cited as a reason for hampered vision. In most of the modern helmet designs, the grill is adjustable. Excessive upward flexion on the helmet and downward flexion on the grill increases this space. Another possible reason may be deformation and compression of the ball after impact. There are incidents of deformation of the grill being pushed inward by the ball. The impact of grill onto the face can lead to severe facial lacerations and contusions. Orbit and maxillary injuries are concomitant with head injuries, but ear injuries are usually rare (Fig. 2).

Concussion injuries to players have also been reported after the sides of the helmet have been hit. Although there is no universally accepted definition of concussion, the textbooks define it as a complex pathophysiological process affecting the brain, induced by traumatic biomechanical forces secondary to direct or indirect forces to the head with essentially normal structural neuroimaging findings. ${ }^{24}$ Concussion injuries are more prevalent following impact to the helmet shell that covers the posterior temporal and occipital regions (Fig. 2).

The earlier research primarily emphasized on the peakfaceguard gap, but video footage of late Phillip Hughes revealed that he was struck by the ball at the angle between the back of the shell and rear of the grill. This seemingly benign impact led to vertebral artery dissection and intracranial hematoma, resulting in death. The helmet manufacturer later declared that Hughes was not wearing a fully protected helmet design (Figs. $1 \mathrm{C}$ and D and 2D). This injury to Phillip Hughes explains the need to extend the helmet shell to cover the occipital area, which has been a rather neglected zone so far. ${ }^{3}$ These kinds of injuries are frustrating too as wearing a helmet provides a false sense of security and not aptly serving its basic purpose. Although there are specific guidelines for helmet design in other sports such as football, no study could definitively prove that wearing a helmet may prevent concussion injury. ${ }^{4,6}$ Existing helmets are designed to prevent catastrophic head injury but not mild head injury such as concussion. To date, the incidence of concussion in cricket is not known.

Hence, the level of protection offered by cricket helmets is a controversial issue, and recent tragic deaths have drawn attention to update the safety standards. The latest update for head protectors in cricket (BS7928) was done in December 2013 but has not been strictly followed since then. ${ }^{19,20}$

\section{Eye Injuries to Wicketkeepers}

In the last 5 decades, there have been several incidents of severe eye injury to players, including career-terminating injuries to Marc Boucher, Saba Karim, and Paul

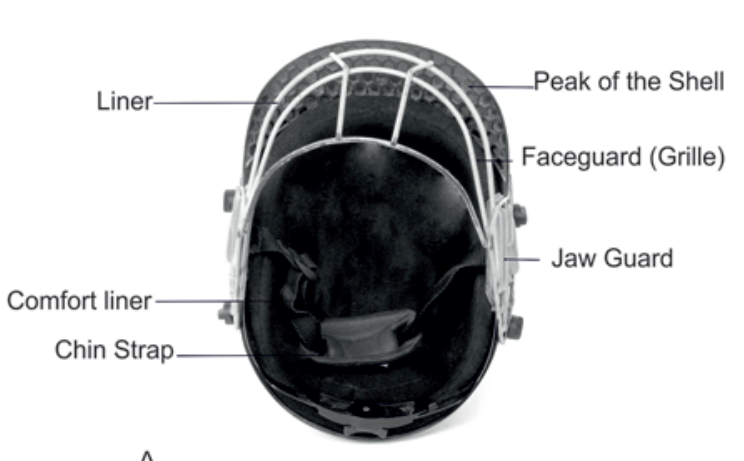

A

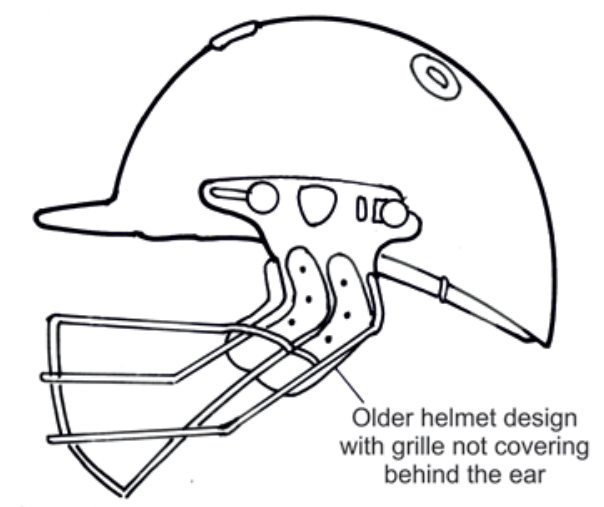

C

FIG. 1. Parts of a cricket helmet. A: Inside view of a helmet showing its liner, shell, chinstrap, grill, and faceguard. B: Lateral view of helmet, screwing system to adjust grill-faceguard gap. C: Popular design of helmet showing limited coverage to mastoid and occiput region. D: Recommended grill design to cover the area behind the ear, as reported by Bolton.
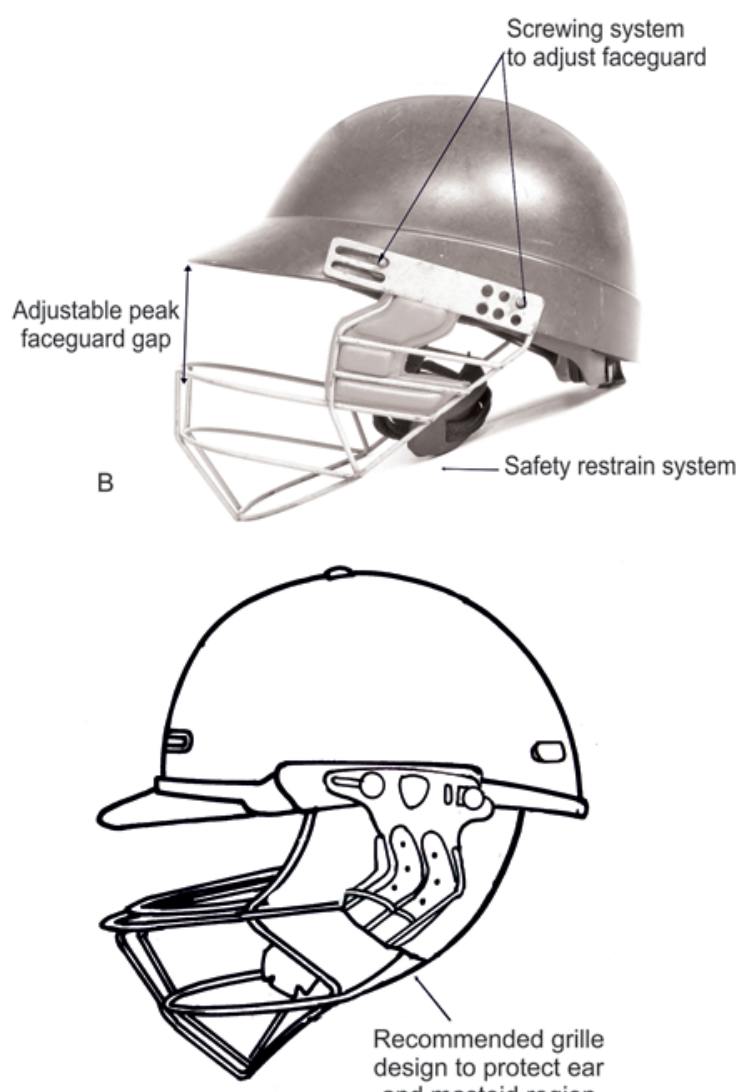

D nd mastoid region 

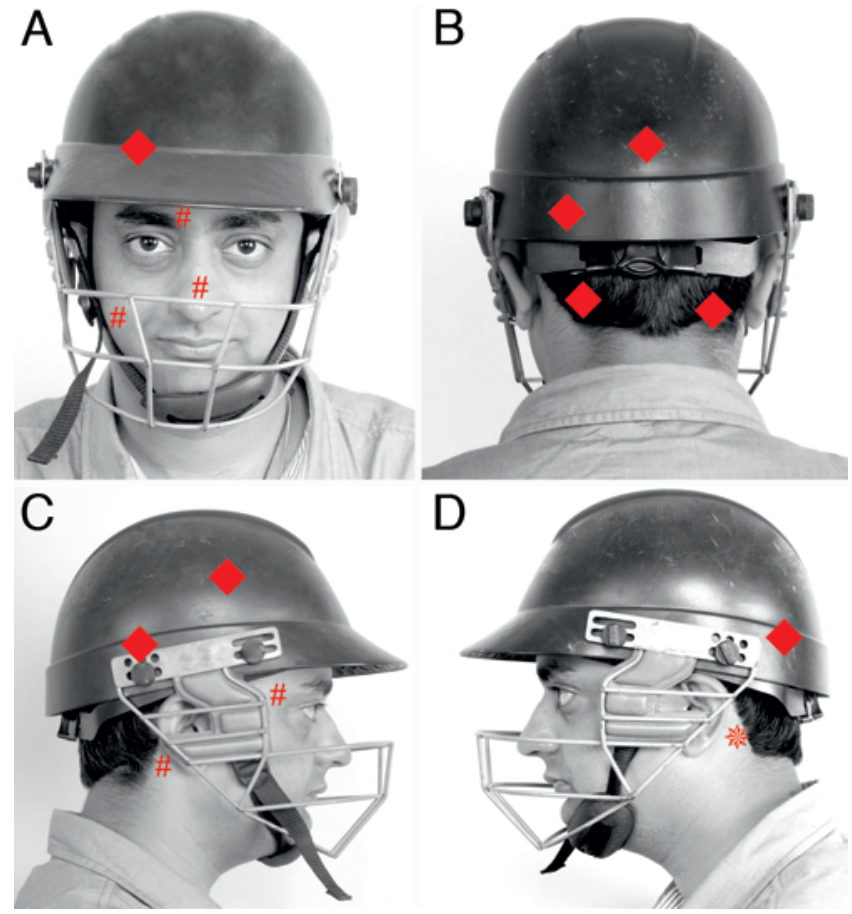

FIG. 2. Common sites of impact and injury pattern: front (A), back (B), right side (C), and left side (D). The pound signs denote fracture; the diamonds, hematoma/concussion; and the star, site of impact to Phillip Hughes. Image inspired by an artistic illustration of impact locations and primary injury type by Ranson et al. ${ }^{28}$

Downton (Table 1). ${ }^{11,15,18}$ A wicketkeeper, on the other hand, is more likely to be hit by the bails rather than by the ball. It is nearly impossible to concentrate on the bail and ball simultaneously. Wicketkeepers are usually more reluctant to wear helmets than are batsmen. As a bail can still hit the eye with a helmet in place, protective eye gear is a must, especially while fielding for a spin bowler. Only polycarbonate-type material meets standard sports specific protective eye gear criteria. Sports-specific eye gear should withstand $18.7 \mathrm{~J}$ (squash) to $114 \mathrm{~J}$ (baseball) of energy transfer. Another recommendation is to change the design of the bails to make their margins less sharp.

\section{Objective Parameters of Helmet Performance}

Drop Test. The drop test is the routinely performed test to compare the strength and safety of cricket helmets (Fig. 3 left and Tables 2 and 3). ${ }^{23,34}$ In this test, the helmet is dropped with the headform onto an anvil, and the acceleration of the headform is measured. For routine purposes, any helmet is considered safe if the head acceleration remains less than $250 \mathrm{~g}\left(250 \times 9.8 \mathrm{~m} / \mathrm{s}^{2}\right)$. However, a few laboratory studies have demonstrated an $80 \%$ likelihood of significant head injuries involving skull fracture or intracranial hemorrhage with an acceleration of $200 \mathrm{~g}$ (Fig. 3 left). The drop test is now criticized, as ball-to-head impact may be significantly more in professional cricket where fast, elite, and express bowlers deliver at speeds of more than 80-100 mph.

Severity Index. The safety of any helmet is measured on an objective scale known as the Severity Index. ${ }^{20}$ The Severity Index score reflects how well a helmet absorbs the energy from an impact by measuring the effects on the head and brain. Helmets with higher severity indices are considered dangerous and more damaging in case of any impact. As per the standards, helmets with severity indices less than 1200 are considered good. However, different biokinetic and laboratory analyses have proved that to prevent a concussion, the severity index should be less than 600 .
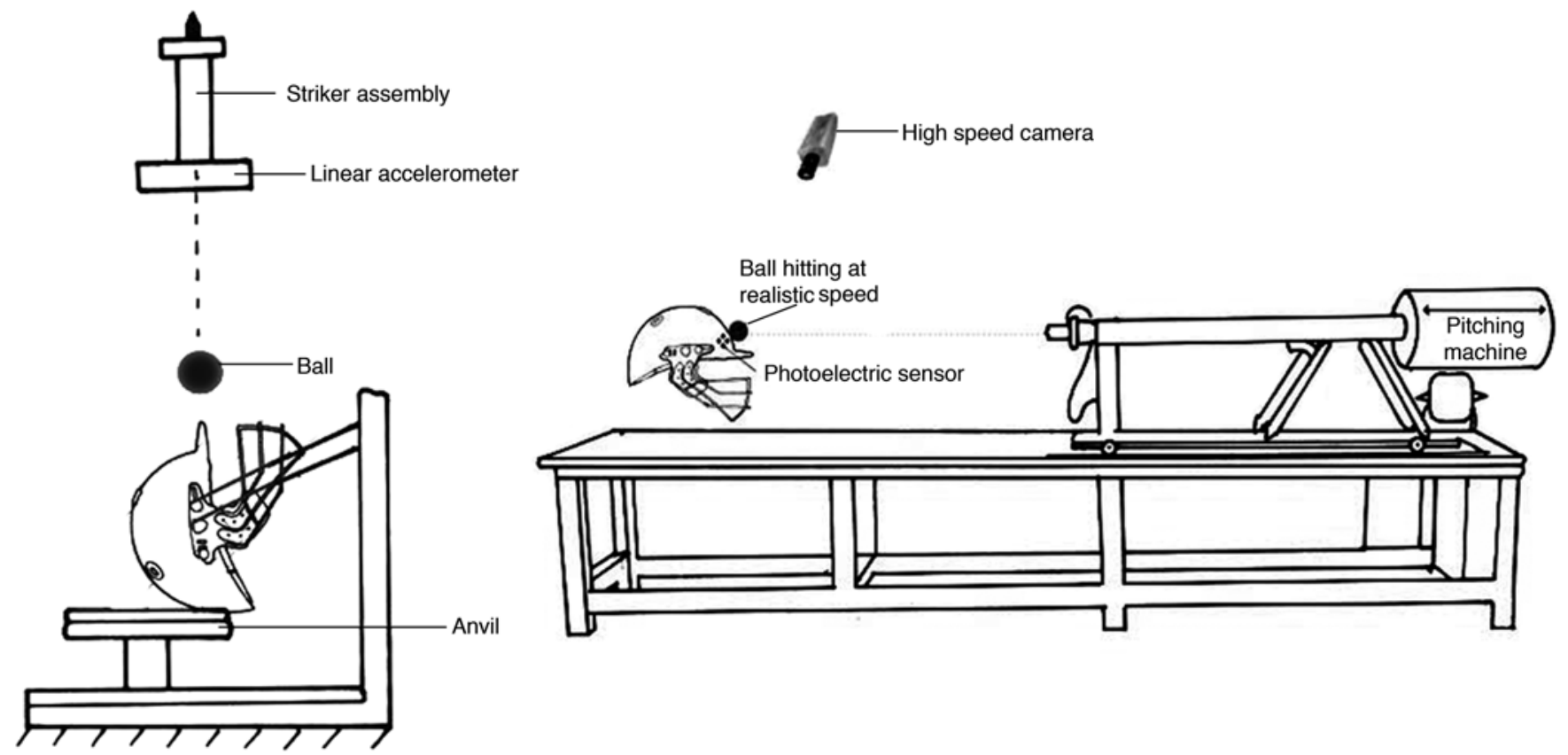

FIG. 3. Illustration of the drop test (left) and air cannon test (right) methodologies for comparative analysis of helmet effectiveness. 
TABLE 2. Research guidelines for safety standards of helmets

\begin{tabular}{|c|c|c|}
\hline Guidelines & Sport & Comments \\
\hline $\operatorname{NOCSAE}^{17}$ & Football & $\begin{array}{l}\text { While the helmets have been designed explicitly as per the guidelines, there is no Level } 1 \text { evidence } \\
\text { proving any benefit for helmet models \& prevention of concussion injury. }\end{array}$ \\
\hline NCAA $^{*}$ & Baseball & $\begin{array}{l}\text { Better replication of the injury pattern using similar types of ball, ball speed, \& replicated the head area } \\
\text { requiring protection. } \\
\text { Includes both drop \& projectile testing. }\end{array}$ \\
\hline $\begin{array}{l}\text { AS/NZS4499: Protective Head- } \\
\text { gear for Cricket, } 199729 \\
\text { BSI specifications for head pro- } \\
\text { tectors for cricketers, } 1998 \\
(B S 7928)^{24}\end{array}$ & Cricket & $\begin{array}{l}\text { A significant number of makers from other countries failed to follow any certified precaution. Most of the } \\
\text { popular helmet models were certified against either of these } 2 \text { standard guidelines. } \\
\text { No analysis of projectile testing. } \\
\text { No provision for helmet/faceguard failure due to contact with the face. } \\
\text { More focused on laboratory research but failed to meet real life dangers such as impact energy levels \& } \\
\text { impact locations. }\end{array}$ \\
\hline Revised BS792824,27 & Cricket & $\begin{array}{l}\text { Included both projectile \& drop test. } \\
\text { Better design at grill \& peak-faceguard gap. }\end{array}$ \\
\hline
\end{tabular}

AS/NZS = Australian/New Zealand Standards; BSI = British Standards Institution; NCAA = National Collegiate Athletic Association; NOCSAE = National Operating Committee for Standards of Athletic Equipment.

* National Collegiate Athletic Association (NCAA): Available at: https://www.ncca.org. Accessed June 12, 2015.

Projectile Test/Air Cannon Test. An air cannon test is an objective method to compare the impact of the injury (Fig. 3 right and Table 2) ${ }^{23,34}$ In this test, a cricket ball is delivered at preset velocities to an enclosure containing a Hybrid III head and neck dummy. Hybrid III is the standard crash test dummy analyzed in frontal crash tests in vehicles. The ball is projected in 2 ways: perpendicular to the surface of the helmet so that the maximum radial force is put toward the center of the helmet, and tangentially to evaluate the other possible patterns of injury. The same area chosen is also checked with different velocities ranging from 45 to $100 \mathrm{mph}$ to evaluate the comparable safety. The energy of impact and the maximum headform acceleration are calculated (Fig. 3 right and Tables 2 and 3).

In a single study of its kind, McIntosh and Janda ${ }^{13}$ did a comparative evaluation of various cricket, hockey, and baseball helmets with projectile and drop tests. Cricket helmets performed poorly in comparison with other sports' helmets when realistic impact was considered. Since every sport exposes its player to a different subset of risks, there cannot be uniform helmet for all sports. Baseball is the only sport that exposes its players to the same risk profile as cricket. The basic purpose of any helmet is to attenuate the impact energy and evenly distribute it over a large surface area to prevent any injury. In comparison with a cricket helmet, a baseball helmet is able to attenuate energy to a greater extent attributable to its 4-times-thicker liner.

\section{Ongoing Research}

Helmet safety is an area of ongoing research, which is receiving multimillion dollar (US) funding from the various manufacturers of sports gear. One important research tool is a head impact device knows as Checklight that measures the impact force. This device was developed and donated by Reebok for National Football League players. ${ }^{7}$ The device is worn under the helmet and features a lightemitting diode on the back of the neck that flashes when a player takes a significant blow. It fits inside the helmet and measures the impact of force from 9 locations around the head. However, it only indicates the strength of impact and nothing about the severity of injury. In a simpler perspective, the Checklight is similar to a traffic signal in that it comprises 3 different colors according to the im-

TABLE 3. Comparative evaluation parameters for helmet performance in cricket*

\begin{tabular}{|c|c|c|}
\hline Variable & Drop Test & Projectile Test/Air Cannon Test \\
\hline Practiced by & Currently practiced routine cricket helmet test method & Recently introduced \& under evaluation in Revised BS7928 criteria \\
\hline Recommended by & AS/NZS 4499.1:1997 \& AS/NZS 2512.3.2:1997 & NOCSAE baseball test method \\
\hline Test methodology & $\begin{array}{l}\text { Helmet is placed on a solid headform, it is struck from } \\
\text { a 2-m height above the point of impact of a helmet } \\
\text { with a falling weight of } 1.5 \mathrm{~kg}, \& \text { deceleration of the } \\
\text { headform is measured }\end{array}$ & $\begin{array}{l}\text { Helmet is fitted on a headform and chinstrap is fastened as per manu- } \\
\text { facturer's instructions; regular cricket balls (mass } 0.156 \mathrm{~kg} \text { ) are fired } \\
\text { at various speeds (19-45 m/sec) from a pitching machine targeting } \\
\text { different points on the helmet }\end{array}$ \\
\hline Analysis of impact & $\begin{array}{l}\text { Impact velocity normal to impact surface is only } 6.4 \\
\text { m/sec (equivalent to } 30 \mathrm{~J} \text { of impact energy); fall on } \\
\text { hemispheric anvil produces maximum deceleration } \\
\text { simulating an injury by cricket ball }\end{array}$ & $\begin{array}{l}\text { At low-velocity impacts (19 m/sec), all cricket helmets reduce the head- } \\
\text { form acceleration by about } 80 \% \text {; at higher velocity }(38-47 \mathrm{~m} / \mathrm{sec}) \text {, } \\
\text { headform acceleration was reduced only by } 40 \%\end{array}$ \\
\hline Comment & Fails to replicate the real ball-helmet impact situation & $\begin{array}{l}\text { Replicates the real ball-helmet impact situation; at } 27-36 \mathrm{~m} / \mathrm{sec} \text {, } \\
\text { headform acceleration begins to exceed safe levels \& helmets fail to } \\
\text { provide protection }\end{array}$ \\
\hline
\end{tabular}

\footnotetext{
* As reported by Pang et al. and Velani et al.
} 
pact: green, yellow, and red. A green signal indicates that a player can be allowed to be on field, yellow indicates that the player should be observed to prevent a successive second hit, and a red signal demands discontinuation for some period as well as further monitoring.

\section{Medico-Legal Concerns}

Although uncommon in cricket, litigation is gradually becoming a common occurrence in other sports. ${ }^{14}$ With the passage of time, when the complete injury profile is realized, there is usually lack of sufficient financial aid and medical benefits, causing families to seek a source of fault for apparently avoidable tragedy to their loved ones.

\section{Initiatives by the ICC}

In 2012, the Federation of International Cricketers' Association and the British Standards Institute have initiated a study aimed at improving safety to the player by wearing a helmet. ${ }^{27}$ The objectives of the committee were to: 1) lay down new safety guidelines; 2) educate the players; 3) encourage research in sports injury; 4) standardize the safety norms for a helmet with consideration of thermal comfort, batting position, and vision; 5) change in the design of bails; 6) lobbying national and international standards organizations to review and improve existing helmet testing protocols; and 7) enforce strict product liability. There should be adequate warnings and instructions for the proper usage of the protective gear provided by the manufacturer.

In view of the insufficient injury reporting, head injury in cricket is viewed as an unfortunate and rare accident or simply "part of the risks of the game." Although an injury risk cannot be negated completely, the chances of significant injuries should be greatly reduced. The purpose of this review article is to highlight the need for better protective gear, appropriate human factors to consider during development of sporting goods and equipment, and adequate binding instructions to players and coaches. Print and electronic media should highlight the safety concerns. An unfortunate event need not be sensational but should be highlighted to prevent its repetition. As a result of increased awareness of sports-related concussion, we can learn about how these injuries occur and how to manage them. It might also help us to understand the mechanism of injury of other sports-related traumatic brain injury.

\section{Suggested Changes in Helmet Design for Contemporary Challenges}

The current helmet design is in need of some changes to reduce risks inherent in cricket. The shell should be fabricated with aerospace-grade carbon fiber/epoxy resin composite, which can afford the realistic impacts on field. ${ }^{13}$ The faceguard (grill) should be extended posteriorly to provide a global coverage to the occiput and temple region behind the ear. The peak-faceguard gap should be adjustable within safety margins only. The faceguard should be made of a tougher material that is tougher than the helmet shell and does not yield in a frontal blow from the speeding ball. The design of the helmet should minimize or prevent the chances of the ball ramming through the peak-faceguard gap. To further reduce the chances of ocular injuries, the peak-faceguard gap should be covered with a visor made of material meeting standard protective eye gear criteria (Fig. 4). However, there should be adequate measures taken to prevent glare and fogging under the visor.

\section{Return-to-Play Guidelines for Cricket}

Cricket adheres to the Zurich consensus, ${ }^{12}$ which states, "a player with diagnosed concussion should not be allowed to [return to play] on the day of injury." The definition of concussion (as applied to cricket) and return-to-play guidelines are debatable and are still evolving. Concussion

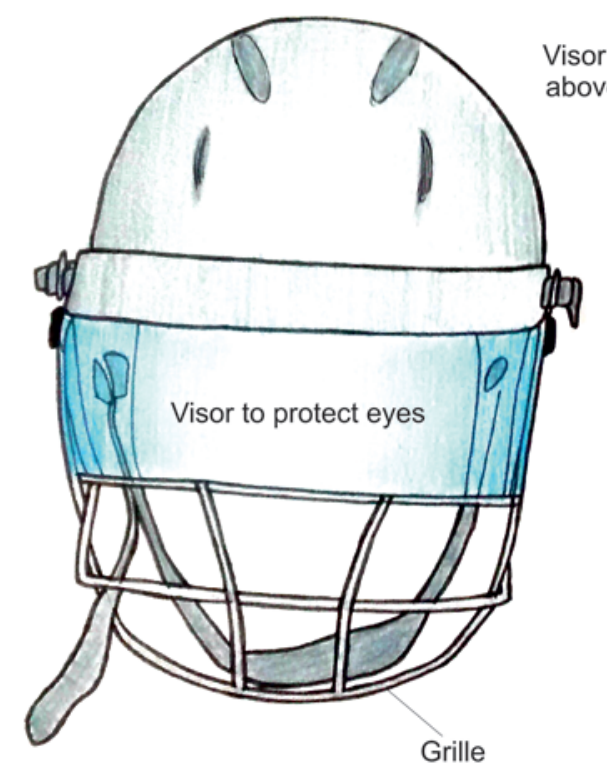

Visor can be adjusted above the face guard

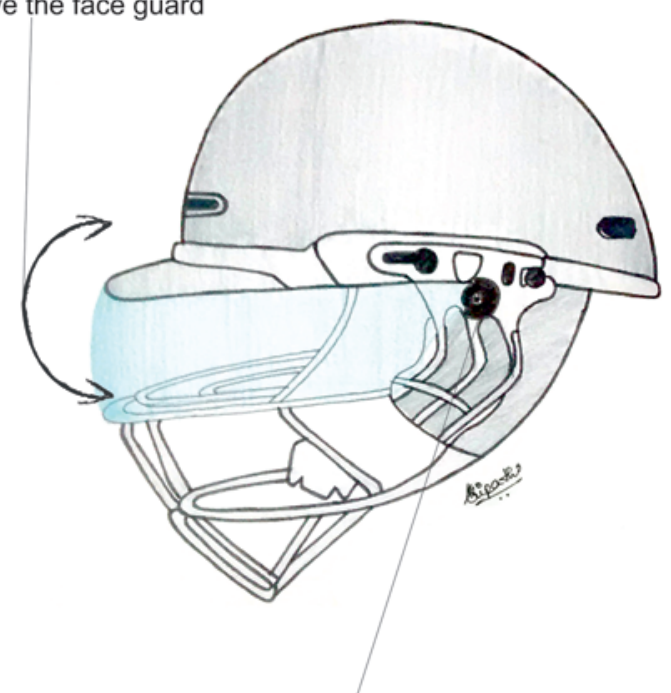

Attachment to adjust visor

FIG. 4. Recommended helmet design for better safety. 
guidelines need to be framed separately for cricket, as the mechanism of injury is different from that in other sports, where the most common cause of injury is direct collision. Concussion is difficult to diagnose in the majority of cases. In such a situation, when the player and coach insist on return to play, logistics demand early return on field to maintain the flow of game. Clinical manifestations of acute concussion may range from physical signs (loss of consciousness, amnesia), behavioral changes, cognitive impairment to sleep disturbance. These symptoms may appear in a few seconds to a few days. When the symptoms of concussion are present, the player should not be allowed to return to play to prevent second impact and wors- en. These players should be subsequently monitored as per the recommended Zurich consensus guidelines (Fig. 5). ${ }^{12}$

\section{Conclusions}

Validation of helmet safety parameters in the laboratory and on field is to be encouraged as per the suggested guidelines discussed here. The batsman and wicketkeeper should wear a helmet while on field. We further emphasize that good-quality helmets should be easily available and affordable even for nonprofessional players. Moreover, all cricket clubs should appoint qualified medical professionals for better surveillance and early identification of injuries and

\section{Injury to Head \\ Suspected Concussion}

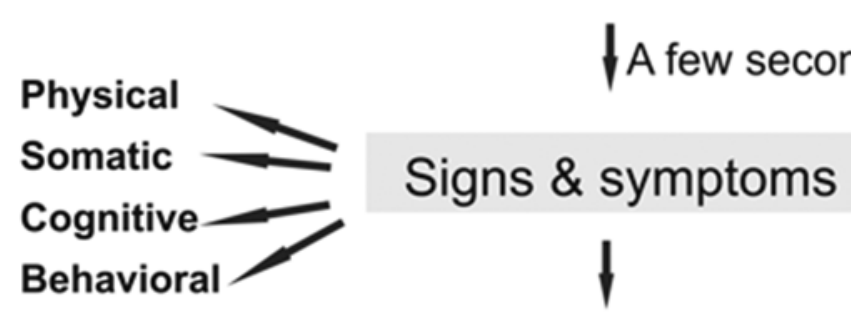

\section{Presence of one/more signs/symptoms}
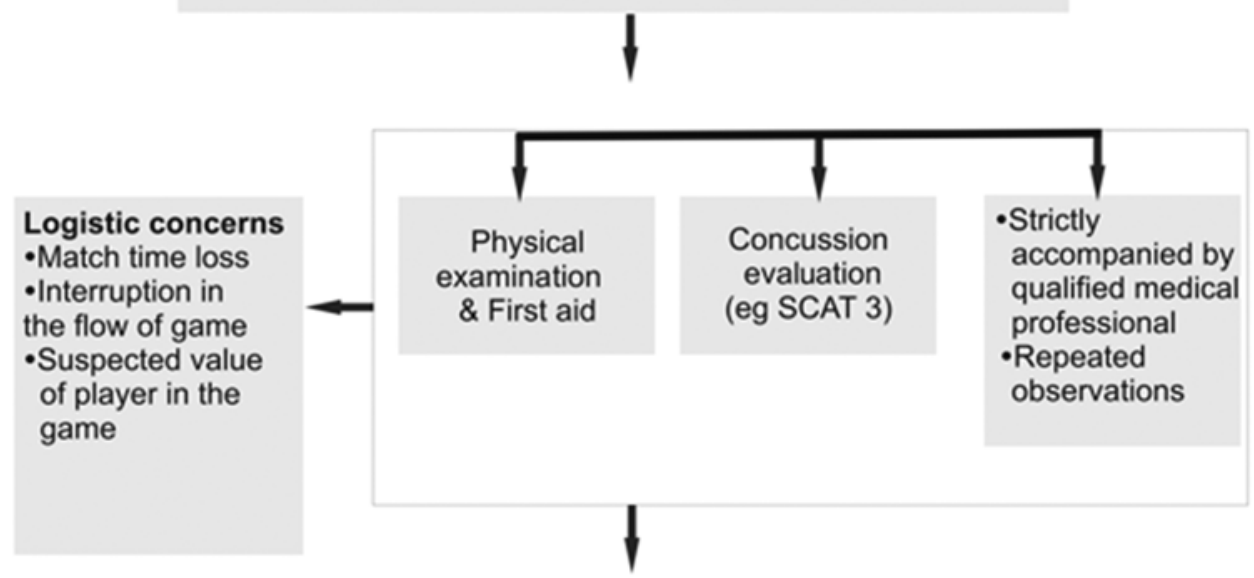

\section{Follow up with the RTP guideline}

(No RTP on the day of injury)

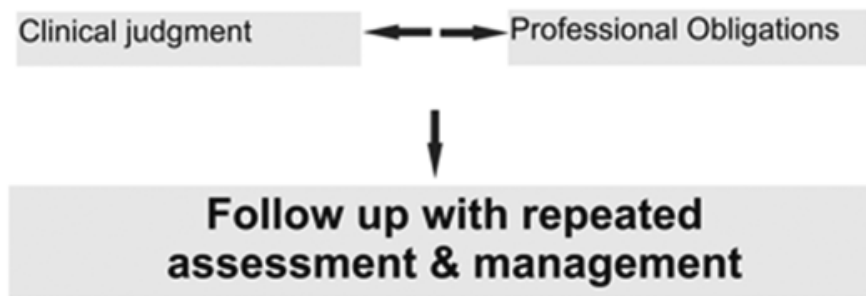

FIG. 5. Proposed guidelines as outlined by McCrory et al. for identification and monitoring of concussion injuries in cricket. RTP = return to play; SCAT3 = Sport Concussion Assessment Tool version 3. 
their management. This might not only prevent fatal events but also premature termination of a bright future.

\section{Acknowledgments}

Sincere thanks to Ms. Shivangi Tripathi (Maharastra Institute of Technology, Pune) and Mr. S. Sripathacharya and Mr. Rajeev V (Department of Mental Health Education, National Institute of Mental Health and Neuro Sciences, Bangalore, India) for their personal assistance in graphics.

\section{References}

1. Bey T, Ostick B: Second impact syndrome. West J Emerg Med 10:6-10, 2009

2. Biasca N, Wirth S, Tegner Y: The avoidability of head and neck injuries in ice hockey: an historical review. Br J Sports Med 36:410-427, 2002

3. Bolton P: Phillip Hughes dies: helmet manufacturer Masuri expresses sympathy with family as they seek answers over his injuries. Telegraph. November 27, 2014. (http://www.telegraph.co.uk/sport/cricket/international/ australia/11253449/Phil-Hughes-latest-Helmet-manufacturerMasuri-to-study-footage-of-incident-that-left-batsman-incritical-condition.html) [Accessed February 17, 2016]

4. Brewster R, Bi WL, Smith TR, Gormley WB, Dunn IF, Laws ER Jr: The neurosurgeon as baseball fan and inventor: Walter Dandy and the batter's helmet. Neurosurg Focus 39(1):E9, 2015

5. Cross KM, Serenelli C: Training and equipment to prevent athletic head and neck injuries. Clin Sports Med 22:639667, 2003

6. Daneshvar DH, Baugh CM, Nowinski CJ, McKee AC, Stern RA, Cantu RC: Helmets and mouth guards: the role of personal equipment in preventing sport-related concussions. Clin Sports Med 30:145-163, x, 2011

7. Dean J: How Reebok is tackling one of the sports world's trickiest problems. Innovation by design 2014. Fast Company Design. September 9, 2014. (http://www.fastcodesign. com/3035264/innovation-by-design-2014/reebok-heads-offinjury) [Accessed February 17, 2016]

8. Finch CF, McIntosh AS, McCrory P: What do under 15 year old schoolboy rugby union players think about protective headgear? Br J Sports Med 35:89-94, 2001

9. International Cricket Council: Members overview. (http:// www.icc-cricket.com/about/96/icc-members/overview) [Accessed February 17, 2016]

10. Lord's: Protective helmet worn by Sunil Mohan Gavaskar. (http://www.lords.org/lords/artefactdetails/ Museum/10620?page=1) [Accessed February 17, 2016]

11. Mann DL, Dain SJ: Serious eye injuries to cricket wicketkeepers: a call to consider protective eyewear. Br J Sports Med 47:607-608, 2013

12. McCrory P, Meeuwisse WH, Aubry M, Cantu B, Dvorák J, Echemendia RJ, et al: Consensus statement on concussion in sport: the 4th International Conference on Concussion in Sport held in Zurich, November 2012. Br J Sports Med 47:250-258, 2013

13. McIntosh AS, Janda D: Evaluation of cricket helmet performance and comparison with baseball and ice hockey helmets. Br J Sports Med 37:325-330, 2003

14. Miller H: Medicolegal aspects of head injury. Curr Med Drugs 7:3-9, 1967

15. Mukherjee A: Head and face injuries in cricket. Cricket Country. August 11, 2014. (http://www.cricketcountry.com/ articles/head-and-face-injuries-in-cricket-part-2-of-3-170004) [Accessed February 17, 2016]

16. Mukherjee A: Head and face injuries in cricket. Cricket
Country. August 11, 2014. (http://www.cricketcountry.com/ articles/head-and-face-injuries-in-cricket-part-2-of-3-170004) [Accessed February 17, 2016]

17. Mukherjee A: Head and face injuries in cricket. Cricket Country. August 11, 2014. (http://www.cricketcountry.com/ articles/head-and-face-injuries-in-cricket-part-3-of-3-170004) [Accessed February 17, 2016]

18. Mukherjee A: Patsy Hendren wears the first helmet in cricket. Cricket Country. June 11, 2015. (http://www. cricketcountry.com/articles/patsy-hendren-wears-the-firsthelmet-in-cricket-294641) [Accessed February 17, 2016]

19. National Operating Committee for Standards of Athletic Equipment (NOCSAE): Standard Performance Specification for Newly Manufactured Football Helmets. (http:// nocsae.org/wp-content/files_mf/1396898424ND00213m13M frdFBHelmetsStandardPerformance.pdf) [Accessed February 17, 2016]

20. Newman J: Criteria for Head Injury and Helmet Standards. (http://www.smf.org/docs/articles/hic/Newman Snell_presentation.pdf) [Accessed February 17, 2016]

21. Orchard J, James T: Cricket Australia 2003 injury report. J Sci Med Sport 6:520-521, 2003

22. Orchard JW: Injury surveillance in cricket. Br J Sports Med 47:605-606, 2013

23. Pang TY, Subic A, Takla M: Impact energy attenuation performance of cricket helmets: standard 2-wire drop test vs. pitching machine impact test. Procedia Eng 60:143-150, 2013

24. Pardini J, Bailes JE, Maroon JC: Mild traumatic brain injury in adults and concussion in sports, in Winn HR (ed): Youmans Neurological Surgery, ed 6. Philadelphia: Saunders Elsevier, 2011, pp 3380-3389

25. Piesse K: Cricket's Colosseum: 125 Years of Test Cricket at the MCG. South Yarra, Australia: Hardie Grant Books, 2003

26. Ranson C: Cricket helmet safety: updating the specification for head protectors, 2013. BSI Group. (https://memberportal. bsigroup.com/premium/2014/decemeber/cricket-helmetsafety-updating-the-specification-for-head-protectors/) [Accessed February 17, 2016]

27. Ranson C, Hurley R, Rugless L, Mansingh A, Cole J: International cricket injury surveillance: a report of five teams competing in the ICC Cricket World Cup 2011. Br J Sports Med 47:637-643, 2013

28. Ranson C, Peirce N, Young M: Batting head injury in professional cricket: a systematic video analysis of helmet safety characteristics. Br J Sports Med 47:644-648, 2013

29. Ranson C, Young M: Putting a lid on it: prevention of batting helmet related injuries in cricket. Br J Sports Med 47:609610, 2013

30. Shaw L, Finch CF: Injuries to junior club cricketers: the effect of helmet regulations. Br J Sports Med 42:437-440, 2008

31. Standards Australia/Standards New Zealand: AS/NZS 4499.1. Protective headgear for cricket. Standards Australia/Standards New Zealand. Homebush, NSW, Australia, 1997

32. Stone P: New study confirms reports that helmets are not effective at preventing concussions. Neurological Rehabilitation Institute at Brookhaven Hospital. (http://www. traumaticbraininjury.net/new-study-confirms-reports-thathelmets-are-not-effective-at-preventing-concussions/) [Accessed February 17, 2016]

33. Stretch R, Raffan R: Injury patterns of South African international cricket players over a two-season period. S Afr J Sports Med 23:45-49, 2011

34. Velani N, Harland AR, Halkon BJ: The development of a test methodology for the determination of cricket batting helmet performance when subjected to ballistic impacts, in IRCOBI 
Conference 2013. Zurich: International Research Council on Biomechanics Injury, 2013, 424-430

35. White GL: Learning from cricket other great clinical stories. Br J Sports Med 47:599, 2013

\section{Disclosures}

The authors report no conflict of interest concerning the materials or methods used in this study or the findings specified in this paper.

\section{Author Contributions}

Conception and design: Tripathi. Acquisition of data: Tripathi,
Mishra. Analysis and interpretation of data: Tripathi. Drafting the article: Tripathi. Critically revising the article: Bhagavatula, Tripathi, Shukla, Bhat. Reviewed submitted version of manuscript: Bhagavatula, Tripathi. Approved the final version of the manuscript on behalf of all authors: Bhagavatula. Statistical analysis: Tripathi. Administrative/technical/material support: Bhagavatula. Study supervision: Bhagavatula, Tripathi.

\section{Correspondence}

Indira Devi Bhagavatula, Department of Neurosurgery, National Institute of Mental Health and Neuro Sciences, Bangalore 560029, India. email: bidevidr@gmail.com. 